\title{
Hypertension in children and adolescents: epidemiology and natural history
}

\author{
Bonita Falkner
}

Received: 12 February 2009 /Revised: 1 April 2009/Accepted: 2 April 2009/Published online: 7 May 2009

(C) IPNA 2009

\begin{abstract}
Primary hypertension is detectable in children and adolescents and, as in adults, is associated with a positive family history of hypertension, obesity, and life-style factors. Owing to the well-established childhood obesity epidemic, the population prevalence of high blood pressure (BP) in the young is increasing. Hypertension in childhood is commonly associated with other cardiovascular risk factors as well as obesity. Although death and cardiovascular disability do not occur in hypertensive children, intermediate markers of target organ damage, such as left ventricular hypertrophy, thickening of the carotid vessel wall, retinal vascular changes, and even subtle cognitive changes, are detectable in children and adolescents with high BP. Considering the rates of verified hypertension $(>3 \%)$ and pre-hypertension $(>3 \%)$ in asymptomatic children and adolescents, high BP should be considered a common long-term health problem in childhood.
\end{abstract}

Keywords Blood pressure · Hypertension ·

Pre-hypertension $\cdot$ Childhood · Adolescence

\section{Introduction}

Hypertension is a major long-term health condition and is the leading cause of premature death among adults throughout the world, including both developed, developing, and lesser developed countries [1]. Primary hypertension emerges from

B. Falkner $(\square)$

Pediatrics and Medicine, Thomas Jefferson University,

833 Chestnut Street, Suite 700,

Philadelphia, PA 19107, USA

e-mail: Bonita.Falkner@jefferson.edu a complex inter-play of genetic, environmental, and behavioral factors. Owing to the hereditary component of hypertension, the disorder is considered to have its origins in the young [2]. It is now established that hypertension is detectable in children and adolescents and is not uncommon. Population changes in health-related behaviors, including the childhood obesity epidemic, indicate that the rates of hypertension in the young are increasing [3]. Several challenges regarding hypertension now confront clinicians who care for children and adolescents and include detecting hypertension, distinguishing secondary hypertension from primary hypertension, examining patients for hypertensionrelated risk factors and target organ damage, applying interventions to control blood pressure (BP), and encouraging preventive lifestyles. This review discusses the epidemiology and natural history of primary hypertension in children and adolescents.

\section{Normative blood pressure data}

The definition of hypertension in adults is based on the approximate level of BP that marks an increase in cardiovascular events and death. Several expert panels have defined hypertension in adults as systolic pressure $\geq$ $140 \mathrm{mmHg}$ or diastolic pressure $\geq 90 \mathrm{mmHg}$ [4-6]. These are the approximate BP levels above which the risks for morbid events is significantly heightened and the benefits of treatment are established. However, it is now recognized that the risk for cardiovascular events attributable to BP level in adults does not begin at $140 / 90 \mathrm{mmHg}$ but is linear, and that the risk begins to rise at BP levels below 140/90 $\mathrm{mmHg}$. For BP levels greater than $115 / 75 \mathrm{mmHg}$, the risk for hypertension-related events doubles with each $20 \mathrm{mmHg}$ increase in systolic pressure or each $10 \mathrm{mmHg}$ increase in 
diastolic BP [7]. Based on these findings in adults, pre-hypertension is defined in adults as systolic BP between $120 \mathrm{mmHg}$ and $139 \mathrm{mmHg}$ or diastolic BP between $80 \mathrm{mmHg}$ and $89 \mathrm{mmHg}$, and lifestyle changes to prevent or delay progression to hypertension are recommended [1].

The definition of hypertension in adults is based on, and supported by, outcome data. Similar data to define hypertension in childhood that are based on risk for events in adult years are not available. Master et al. [8] published a report in 1950 that challenged the use of a single number to define hypertension in adults. They contended that an increase in BP was a reflection of aging and that hypertension was over-diagnosed in the elderly. Because $\mathrm{BP}$, like most human characteristics, demonstrates a frequency distribution that yields a fairly normal curve, they proposed that BP that reached a level that was two standard deviations beyond the statistical mean, or greater than the 95th percentile, should be considered abnormal. Using a statistical method to define the normal range of BP, they described the normal range of systolic BP in young men to be $105-135 \mathrm{mmHg}$ at age 16 years, rising progressively with age to reach $115-170 \mathrm{mmHg}$ at age 60-65 years. They also noted a gender difference in the normal range of BP, with lower levels in younger women than in younger men. A large body of subsequent epidemiological and clinical investigations on hypertension in adults has clearly dismissed the conclusion by Master et al. that hypertension should be statistically defined in adults. However, their report was the earliest to show that the normal range of BP is lower in persons aged 1619 years than that in early adulthood, and gender differences were also identified. Of most significance is that their report provided a statistical method to define the normal BP range, and abnormal $\mathrm{BP}$ could be defined in the absence of mortality or morbidity end points.

The early efforts to describe the normal range BP according to age throughout childhood reported markedly different results [9]. In a recent analysis, Din-Dzietham et al. [10] applied the 95th percentile definition of high BP, based on the most current BP percentile tables, published in 2004 [2], to the data from the early surveys on children's BP. As shown in their report, in using the current BP level for the 95th percentile (by age and gender), they found that the rates of high BP in the earlier surveys were astonishingly high. According to current BP levels for the 95th percentile, the overall estimated prevalence of high BP among children in the 1963-1970 survey would have been $37.2 \%$; in the 1971-1975 survey it decreased to $16.9 \%$; in the $1976-1980$ it decreased to $11.1 \%$. By $1982-1984$ the prevalence was $4.7 \%$, and the lowest was $2.7 \%$ in the 1988 1994 survey. The earliest childhood BP surveys were, in general, based on a single BP measurement, and a standardized method for BP measurement was not uniformly applied. It is unlikely that the prevalence of high BP was so high in 1963 and that the prevalence would have changed so drastically from 1963 to 1994 . What changed was the body of normative BP data from which the BP percentiles were derived [11]. The need to obtain a larger body of data on BP in the young within the context of childhood growth was recognized by the National Heart, Lung, and Blood Institute (NHLBI) in the 1970s. The NHLBI subsequently supported several epidemiological studies that prospectively investigated BP and growth in children and adolescents. These projects were conducted at several sites and enrolled representative samples of children and adolescents. Rigorous detail was applied to the methodology of BP measurement. Growth and development measures were obtained, and BP level was examined relative to physiological development. This collective body of children's BP data provided the data on BP distribution reported in the second Task Force on Blood Pressure in Children and Adolescents [12]. Subsequently, there was little shift in the distribution of children's BP [13] until the recent upward trend attributed to the rising rates of childhood obesity $[3,10]$.

Rather than a single BP level, the top portion of the distribution of BP specific to age, gender, and height continues to be used to define high BP throughout childhood. Hypertension in childhood is defined as systolic and/or diastolic BP that is $\geq 95$ th percentile for age, gender, and height. Previously, children with BP levels $\geq 90$ th percentile but $<95$ th percentile were termed high normal. To be consistent with adult terms, and the concept that BP risks are linear rather than categorical, this term been changed to pre-hypertension. Therefore, pre-hypertension is defined as systolic and/or diastolic BP that is $>90$ th percentile (for age, gender, and height) but $<95$ th percentile. However, this designation remains arbitrary and without supportive childhood evidence. Moreover, in adolescence, the 90th percentile is often higher than the adult threshold for pre-hypertension of 120/80 $\mathrm{mmHg}$. Therefore, beginning for children aged 12 years, prehypertension is defined as BP levels in the range of 120/ $80 \mathrm{mmHg}$ to the 95 th percentile. The rationale for this definition is based on the findings that the risk for events in adults begins to rise at a BP level above $115 / 75 \mathrm{mmHg}$, and that, for clinical purposes, adolescents could benefit from preventive lifestyle interventions as well as adults. BP levels that are consistently above the 95th percentile are staged for severity. Stage 1 hypertension is defined as an average BP level from the 95th percentile to $5 \mathrm{mmHg}$ above the 99th percentile. Stage 2 hypertension is defined as an average BP that exceeds $5 \mathrm{mmHg}$ above the 99th percentile. Owing to BP variability within individual patients, in clinical practice the diagnoses of hypertension and pre-hypertension require repeated measurements [2]. In adults the diagnosis of hypertension is verified by $\mathrm{BP} \geq 140$ / $90 \mathrm{mmHg}$ on two separate visits. To avoid over-diagnosis 
of hypertension in a child with a single elevated BP, three separate visits for BP measurement are recommended, with an average $\mathrm{BP} \geq 95$ th percentile required for diagnosis of hypertension. An exception to the necessity for repeated BP measurement would be stage 2 hypertension or a child with symptomatic hypertension.

In other countries the BP percentile level that is used to define high BP in children varies somewhat from the US definitions described above. High BP in the UK is defined as BP above the 98th percentile for age [14]. BP reference values have also been reported in Northern Europe [15] and Asia [16]. These reports describe a slightly higher BP level at the 95th percentile. However, all epidemiological reports on normative childhood BP data demonstrate a consistent and significant relationship of BP with age, height, and body weight throughout childhood.

\section{Prevalence of childhood hypertension}

The prevalence of pediatric hypertension worldwide is not known, due to regional differences in the definition of high $\mathrm{BP}$, the distribution of reference BP data, and the BP measurement methodology. Based on the use of $\geq 95$ th percentile to define hypertension, it would be expected that the prevalence of hypertension would be approximately $5 \%$. However, due to the effects of accommodation and regression to the mean with repeated measures, the prevalence of hypertension is lower than $5 \%$ and had been expected to be from 1-3\% following the recommended three separate measurements in children with an initial BP measurement $\geq 95$ th percentile.

Recent reports have provided a more precise estimate of the prevalence of hypertension verified by separate measurements. In a recent study Hansen et al. [17] applied the above criteria for hypertension and pre-hypertension to electronic medical record data from well-child care visits in a cohort of over 14,000 primary care patients. With the advantage of having data on repeat BP measurements on separate visits, these investigators determined the prevalence of hypertension to be $3.6 \%$ and the prevalence of prehypertension to be $3.4 \%$ in children and adolescents between the ages of 3 years and 18 years. In a cross-sectional study limited to the adolescence age, the prevalence of prehypertension and hypertension was determined in a cohort of 6,790 high school students (11-17 years). Using the recommended repeated BP measurements on those with an elevated initial BP measurement, the authors found that the prevalence of hypertension was $3.2 \%$ and the prevalence of pre-hypertension was $15.7 \%$ in adolescence [18]. In both reports the presence of obesity was associated with higher rates of high BP. In the study on high school students by McNiece et al. [18] the prevalence of hypertension and pre- hypertension combined was over $30 \%$ in obese boys and from $23-30 \%$ in obese girls, depending on ethnicity.

The current childhood obesity epidemic [19] and the strong relationship of BP with body weight indicate that the population prevalence of high $\mathrm{BP}$ in the young will increase. The epidemiologic evidence to support an adverse impact of childhood obesity on child BP levels has been questioned because, as discussed previously, the earlier population data on children's BP (from the 1963-1984) described considerably higher $\mathrm{BP}$ values than in the data obtained after 1984 [20]. When the entirety of the data from the children's BP survey from 1963 to 1994 is compared, it would appear that children's BP levels are decreasing, despite an increase in child obesity within the past decade. However, the variable methods used in the earlier BP surveys limit the ability for us to define a longitudinal trend in children's BP over several decades. An analysis of the trends in childhood BP from two more recent studies by the National Health and Nutrition Examination Surveys (NHANES) group, which were sequential, national and cross-sectional, identified a significant increase in both systolic and diastolic BPs. The BP increase is most striking among minority groups that also have the highest rates of childhood obesity [3]. Another analysis of the same two data cohorts demonstrated an overall increase in the prevalence of hypertension, from $2.7 \%$ in the $1988-1994$ survey to $3.7 \%$ in the 1999-2002 survey [10]. Both analyses verified that the population increase in BP among children and adolescents was largely due to the increase in obesity.

\section{Incidence of hypertension in childhood}

Among adults, the prevalence of hypertension increases with age, indicating that new cases of hypertension in adults are diagnosed each year. Although primary hypertension is more commonly identified in adolescence than earlier in childhood, there is little information about the incident rates of hypertension in childhood. Within the National Childhood Blood Pressure database, a segment of adolescents underwent BP measurement at intervals of 2 years and 4 years. An analysis of these data found that, among adolescents with pre-hypertension, $14 \%$ had developed hypertension 2 years later, which yielded an approximate incidence rate of $7 \%$ per year. A limitation of these data is that they were based on only a single blood pressure measurement for BP classification. Despite this limitation, the serial data indicate that those with high BP continue to have high BP. Among adolescents with high risk BP values, including those designated from a single measurement as having prehypertension and hypertension combined, $68 \%$ of boys and $43 \%$ of girls had developed pre-hypertension or hypertension 2 years later [21]. 
Despite the well-known variability in serial BP measurements in children, there is now substantial evidence that BP measured in childhood predicts future BP. Those with BP levels in the higher portions of the distribution curve tend to maintain that position over time which is indicative of BP tracking [22]. For example, a community study of 1,505 children aged 5-14 years demonstrated tracking of systolic and diastolic BPs over 15 years, with statistically significant correlation coefficients between childhood BP and later BP levels. Of 116 young adult participants who had developed hypertension, $48 \%$ and $41 \%$ had suffered elevated childhood systolic and diastolic BPs, respectively [23]. The patterns may vary by race, but weight does not seem to affect population tracking data significantly $[24,25]$.

A recent systematic review and analysis of 50 cohort studies that examined BP tracking documented significant BP tracking correlation coefficients from childhood into adulthood. The strength of the tracking increased with baseline age and decreased with length of follow-up period. The analysis concluded that data from diverse populations show that the evidence for BP tracking from childhood into adulthood is strong and that early intervention is important [26]. In another study Sun et al. [27] examined serial data from participants in the Fels Longitudinal Study and derived age- and gender-specific BP levels in childhood that predicted hypertension in adulthood. Using randomeffects models they found that the earliest significant difference in childhood systolic BP values among adults with and without hypertension occurred at age 5 years for boys and 8 years for girls. The interesting finding from this study was the level of childhood BP that was predictive of subsequent hypertension in adults. The age- and genderspecific values for childhood systolic BP among adults with hypertension were below the 50th percentile for systolic BP in children of median height, based on data in the Fourth report on diagnosis, evaluation, and treatment of high blood pressure in children and adolescents [2]. Therefore, the childhood systolic BP values in the Fels Longitudinal Study that were predictive of future hypertension in adults were well below childhood BP levels that are presently considered to be high risk. These results raise the question of whether the 95th percentile or the 90th percentile for BP in childhood adequately captures high risk BP.

\section{Outcomes of childhood onset hypertension}

There are presently no long-term data to connect a level of childhood BP with cardiovascular events in later adulthood. Despite the absence of such longitudinal data to assess outcome risk among adolescents with high BP, data on surrogate markers of vascular injury indicate that vascular abnormality does occur even in the young. Left ventricular hypertrophy (LVH) occurs commonly in children and adolescents with high BP [28-31]. Among children and adolescents with primary hypertension, the presence of obesity was associated with marked LVH [28]. Structural changes in forearm vessels of obese adolescents with high BP were detected by Rocchini et al. [32], who observed a significant correlation between peripheral vascular resistance at maximum vasodilation and measures of insulin resistance. Carotid artery intimal medial thickness (cIMT), assessed by ultrasound, has been found to be greater in young adults who had had multiple risk factors since childhood [33-35]. In a smaller cross-sectional study an increase in cIMT was already detectable in adolescents with high BP [36]. Microalbuminuria predicts progressive deterioration of renal function and an increased risk of cardiovascular (CV) events/death in adults. Recently, Assadi demonstrated that, in children with essential hypertension, the treatment of microalbuminuria by renoprotective therapy (angiotensinconverting enzyme inhibitors or angiotensin-receptor blockers) was associated with LVH regression [37]. The Pathologic Determinants of Atherosclerosis in Youth study, based on autopsies of individuals that had suffered accidental death, demonstrated that quantifiable vessel injury is detectable in adolescents and young adults; and there is a relationship, even in youth, between early atherosclerotic lesions and cardiovascular risk factors, including high BP, altered lipids, and smoking exposure [38, 39]. In a recent study by Mitchell et al. [40] digital retinal photographs were used to measure retinal arteriolar caliber in children. The investigators observed that children in the highest quartile of BP had significantly narrower retinal arterioles than those with lower BP, suggesting that higher BP in childhood is associated with alteration in the microvasculature. There is even emerging evidence that cognitive function is adversely affected by elevated blood pressure in childhood [41, 42].

\section{Summary}

It is well established that high BP can be identified in children and adolescents [2], and is increasing in prevalence $[3,10]$. However, the definition of hypertension continues to be based on the upper segment of the normal BP distribution and not on outcome data. It is quite possible that the percentiles currently used to define hypertension and pre-hypertension in childhood underestimate the longitudinal risk; and future evidence may warrant a lower level to define high risk BP. Despite the meticulous precision in the BP tables, which adjust for gender, age, and height, the percentile method for the evaluation of BP in children is cumbersome and difficult to use in clinical practice. It would be an extremely useful clinical practice advancement if a few numerical levels could be reliably 
used for the evaluation of children's BP. However, for one to be certain of what BP value is abnormal, there needs to be clear evidence on where the abnormality begins. What is clear is that more BP measurements on an individual child provide a better definition of the BP phenotype. Ambulatory BP monitoring (ABPM) has become a useful tool for evaluating $\mathrm{BP}$ patterns in children, and some normative ABPM data are now available. Because ABPM is performed over 24 hours and requires special instrumentation, its use has been generally limited to hypertension specialists. Recommendations on the use of ABPM in clinical practice and interpretation of the results have been published recently in a scientific statement from the American Heart Association [43].

Data from clinical studies on high BP in childhood show that primary hypertension in childhood is commonly associated with other cardiovascular risk factors as well as obesity. It is also apparent that intermediate markers of target organ damage, such as LVH, increased cIMT, retinal vascular changes, and even subtle cognitive changes, are detectable in children and adolescents with high BP. Considering the rates of verified hypertension $(>3 \%)$ and pre-hypertension $(>3 \%)$ in asymptomatic children and adolescents, we should consider high BP as a common long-term health problem in childhood. For both clinical and public health benefit, identification, examination, and treatment of children with high risk BP is an important step in reducing the excessive burden of cardiovascular disease.

\section{Questions}

(Answers appear following the reference list)

1. Hypertension is defined in adolescents as:
a. Average $\mathrm{BP} \geq 140 / 90 \mathrm{mmHg}$
b. Average $\mathrm{BP} \geq 120 / 80 \mathrm{mmHg}$
c. Average $\mathrm{BP} \geq 95$ th percentile
d. Average $\mathrm{BP} \geq 90$ th percentile

2. The definition of hypertension in children and adolescents is based on:
a. The top portion of the normal distribution of BP levels in healthy children
b. Outcome data
c. Evidence of target organ damage
d. Two additional cardiovascular risk factors

3. A single BP measurement of $136 / 74 \mathrm{mmHg}$ in an asymptomatic 12 year old boy indicates:
a. Essential hypertension
b. Need for repeat BP measurement
c. Probable secondary hypertension
d. Risk for cardiovascular disease

4. The prevalence of hypertension in asymptomatic children and adolescents is approximately:
a. $<1 \%$
b. $3.5 \%$
c. $5 \%$
d. $10 \%$

5. A recent increase in prevalence of childhood hypertension is most related to:
a. Improved methods of BP measurement
b. Changes in diet and food supply
c. Ethnic shifts in the population
d. Childhood obesity

\section{References}

1. Chobanian AV, Bakris GL, Black HR, Cushman WC, Green LA, Izzo JL Jr, Jones DW, Materson BJ, Oparil S, Wright JT Jr, Roccella EJ (2003) The seventh report of the joint national committee on prevention, detection, evaluation, and treatment of high blood pressure: the JNC 7 Report. JAMA 289:2560-2572

2. National High Blood Pressure Education Program Working Group on High Blood Pressure in Children and Adolescents (2004) The fourth report on the diagnosis, evaluation, and treatment of high blood pressure in children and adolescents. Pediatrics 114:555576

3. Munter P, He J, Cutler JA, Wildman RP, Whelton PK (2004) Trends in blood pressure among children and adolescents. JAMA 291:2107-2113

4. The sixth report of the joint national committee on prevention, detection, evaluation, and treatment of high blood pressure (1997) NIH publication no. 98-4080, November 1997

5. McAlistar FA, Campbell NR, Zamke K, Levine M, Graham ID (2001) The management of hypertension in Canada: a review of current guidelines, their shortcomings and implications. CMAJ 164:517-522

6. Guidelines Subcommittee (1999) 1999 World Health Organization-International Society of Hypertension guidelines for the management of hypertension. J Hypertens 17:151-183

7. Vasan RS, Larson MG, Leip MS, Evans JC, O’Donnell CJ, Kannel WB, Levy D (2001) Impact of high normal blood pressure on the risk of cardiovascular disease. N Engl J Med 345:1291-1297

8. Master AM, Dublin LI, Marks HH (1950) The normal blood pressure range and its clinical implications. JAMA 143:1464 1470

9. Roberts J, Maurer K (1977) Blood pressure of youths 12-17 years: United States. Data from The National Health Survey. Vital and Health Statistics series 11:iii-vi, pp 1-62

10. Din-Dzietham R, Liu Y, Bielo M-V, Shamsa F (2007) High blood pressure trends in children and adolescents in national surveys. 1963 to 2002. Circulation 116:1488-1496

11. Falkner B (2007) What exactly do the trends mean? Circulation 116:1437-1439

12. National Heart, Lung, and Blood Institute (1987) Report of the second task force on blood pressure control in children-1987. Pediatrics 79:1-25

13. Rosner B, Cook N, Portman R, Daniels S, Falkner B (2008) Determination of blood pressure percentiles in normal weight children: some methodological issues. Am J Epidemiol 167:653-666 
14. Jackson LV, Thalange NK, Cole TJ (2007) Blood pressure percentiles for Great Britain. Arch Dis Child 92:298-303

15. Munkhaugen J, Lydersen S, Wideroe T-E, Hallan S (2008) Blood pressure reference values in adolescents: methodological aspects and suggestions for Northern Europe tables based on the NordTrondelag Health Study II. J Hypertens 26:1912-1918

16. Sung RYT, Choi KC, So H-K, Nelson EAS, Li AM, Kwok CWL, Tong GN, Mak KH, Ng PC, Fok TF (2008) Oscillometrically measured blood pressure in Hong Kong Chinese children and associations with anthropometric parameters. J Hypertens 26:678-684

17. Hansen ML, Gunn PW, Kaelber DC (2007) Underdiagnosis of hypertension in children and adolescents. JAMA 298:874-879

18. McNiece KL, Poffenbarger TS, Turner JL, Franco KD, Sorof JM, Portman RJ (2007) Prevalence of hypertension and prehypertension among adolescents. J Pediatr 150:640-644

19. Ogden CL, Flegel KM, Carroll MD, Johnson CL (2002) Prevalence and trends in overweight among US children and adolescents, 1999-2000. JAMA 288:1728-1732

20. Chiolero A, Bovet P, Paradis G, Paccaud F (2007) Has blood pressure increased in children in response to the obesity epidemic? Pediatrics 119:544-553

21. Falkner B, Gidding SS, Portman R, Rosner B (2008) Blood pressure variability and classification of prehypertension and hypertension in adolescence. Pediatrics 122:238-242

22. Gidding SS (2008) Measuring children's blood pressure matters. Circulation 117:3163-3164

23. Bao W, Threefoot SA, Srinivasan SR, Berenson GS (1995) Essential hypertension predicted by tracking of elevated blood pressure from childhood to adulthood: the Bogalusa Heart Study. Am J Hypertens 8:657-665

24. Fuentes RM, Notkolab IL, Shemeikka S, Tuomilehto J, Nissinen A (2002) Tracking of systolic blood pressure during childhood: a 15-year follow-up population-based family study in eastern Finland. J Hypertens 20:195-202

25. Donahue RP, Prineas RJ, Gomez O, Hong CP (1994) Tracking of elevated systolic blood pressure among lean and overweight adolescents: the Minneapolis Children's Blood Pressure Study. J Hypertens 12:303-308

26. Chen X, Wang Y (2008) Tracking of blood pressure from childhood to adulthood: a systematic review and meta-regression analysis. Circulation 117:3171-3180

27. Sun SS, Grave GD, Siervogel RM, Pickoff AA, Arslanian SS, Daniels SR (2007) Systolic blood pressure in childhood predicts hypertension and metabolic syndrome later in life. Pediatrics 119:237-246

28. Daniels SR, Loggie JMH, Khoury P, Kimball TR (1998) Left ventricular geometry and severe left ventricular hypertrophy in children and adolescents with essential hypertension. Circulation 97:1907-1911

29. Hanevold C, Waller J, Daniels S, Portman R, Sorof J (2004) The effects of obesity, gender, and ethnic group on left ventricular hypertrophy and geometry in hypertensive children: a collaborative study of the International Pediatric Hypertension Association. Pediatrics 113:328-333

30. McNiece KL, Gupta-Malhotra M, Samuels J, Bell C, Garcia K, Poffenbarger T, Sorof JM, Portman RJ, National High Blood Pressure Education Program Working Group (2007) Left ventricular hypertrophy in hypertensive adolescents: analysis of risk by 2004 National High Blood Pressure Education Program Working Group staging criteria. Hypertension 50:392-395

31. Brady TM, Fivush B, Flynn FT, Parekh R (2008) Ability of blood pressure to predict left ventricular hypertrophy in children with primary hypertension. J Pediatr 152:73-78

32. Rocchini AP, Moorehead C, Katch V, Key J, Finta KM (1992) Forearm resistance vessel abnormalities and insulin resistance in obese adolescents. Hypertension 19:615-620
33. Raitakari OT, Juonala M, Kahonen M, Taittonen L, Laitinen T, Maki-Torkko N, Jarvisalo MJ, Uhari M, Jokinen E, Ronnemaa T, Akerblom HK, Viikari JSA (2003) Cardiovascular risk factors in childhood and carotid artery intima-media thickness in adulthood: the Cardiovascular Risk in Young Finns Study. JAMA 290:22772283

34. Oren A, Vos LE, Uiterwaal CSPM, Gorissen WHM, Grobbee DE, Bots ML (2003) Change in body mass index from adolescence to young adulthood and increased carotid intima-media thickness at 28 years of age: The Atherosclerosis Risk in Young Adults study. Int J Obes 27:1383-1390

35. Li S, Chen W, Srinivasan SR, Bond MG, Tang R, Urbina EM, Berenson GS (2003) Childhood cardiovascular risk factors and carotid vascular changes in adulthood. The Bogalusa Heart Study. JAMA 290:2271-2276

36. Sorof JM, Alexandrov AV, Garami Z, Turner JL, Grafe RE, Lai D, Portman RJ (2003) Carotid ultrasonography for detection of vascular abnormalities in hypertensive children. Pediatr Nephrol 18:1020-1024

37. Assadi F (2007) Effect of microalbuminuria lowering on regression of left ventricular hypertrophy in children and adolescents with essential hypertension. Pediatr Cardiol 28:27-33

38. Berenson GS, Wattigney WA, Tracy RE, Newman WP, Srinivasan SR, Webber LS, Dalferes ER Jr, Strong JP (1992) Atherosclerosis of the aorta and coronary arteries and cardiovascular risk factors in persons aged 6 to 30 years and studied at necropsy (The Bogalusa Heart Study). Am J Cardiol 70:851-858

39. McGill HC Jr, McMahan CA, Malcom GT, Oalmann MC, Strong JP (1995) Relation of glycohemoglobin and adiposity to atherosclerosis in youth. Pathobiological Determinants of Atherosclerosis in Youth (PDAY) Research Group. Arterioscler Thromb Vasc Biol 15:431-440

40. Mitchell P, Cheung N, de Haseth K, Taylor B, Rochtchina E, Islam FMA, Wang JJ, Saw SM, Wong TY (2007) Blood pressure and retinal arteriolar narrowing in children. Hypertension 49:1156-1162

41. Lande MB, Kaczorowski JM, Auinger P, Schwartz GJ, Weitzman M (2003) Elevated blood pressure and decreased cognitive among school-age children and adolescents in the United States. J Pediatr 143:720-724

42. Lande MB, Adams H, Falkner B, Waldstein SR, Schwartz GJ, Szilagyi PG, Wang H, Palumbo D (2009) Parental assessments of internalizing and externalizing behavior and executive function in children with primary hypertension. J Pediatr 154:207-212

43. Urbina E, Alpert B, Flynn J, Hayman L, Harshfield GA, Jacobson M, Mahoney L, McCrindle B, Mietus-Snyder M, Steinberger J, Daniels S (2008) Ambulatory blood pressure monitoring in children and adolescents: recommendations for standard assessment. A scientific statement from the American Heart Association Atherosclerosis, Hypertension, and Obesity in Youth Committee of the Council on Cardiovascular Disease in the Young and the Council for High Blood Pressure Research. Hypertension 52:433-451
Answers
1. c.
2. a.
3. b.
4. b.
5. d. 